\title{
ANÁLISE ESTATÍSTICA MULTIVARIADA DE ÁGUAS SUBTERRÂNEAS NA BACIA DO RIO URUSSANGA
}

\section{MULTIVARIATE STATISTICAL ANALYSIS OF UNDERGROUND WATERS IN THE URUSSANGA RIVER BASIN}

\section{William de Oliveira Santana \\ Centro Tecnológico - SATC/SC. E-mail: william.santana@satc.edu.br \\ Daniel Pazini Pezente \\ Programa de Pós-Graduação em Ciências Ambientais - PPGCA/UNESC. E-mail: daniel.pezente@satc.edu.br}

\section{RESUMO}

Os aquíferos são importantes reservas estratégicas que devem ter seus usos prescritos após estudos. Localizada no sul do estado de Santa Catarina, a Bacia do Rio Urussanga compreende $680 \mathrm{Km}^{2}$, nos quais se apresentam diversos usos dos recursos hídricos. Com o objetivo de analisar a qualidade das águas subterrâneas da bacia, analisaram-se propriedades geoquímicas destas águas e a espacialização dos poços. Com 30 pontos de coleta de água subterrânea analisou-se doze variáveis: cálcio, potássio, sódio, cloreto, sulfatos, magnésio, manganês, ferro, alumínio, $\mathrm{pH}$, condutividade elétrica e alcalinidade total. As águas provêm de poços tubulares, poços escavados, ponteiras e fontes, denotando a captação em diferentes intervalos aquíferos. Utilizando-se de softwares estatísticos, elaboraram-se gráficos, para uma Análise de Componentes Principais (ACP) e de agrupamento. O cruzamento das análises permitiu concluir que as águas do aquífero profundo ainda estão sem interface com águas superficiais, sendo estas já poluídas. A síntese dos resultados estatísticos permitiu a construção de panorama sobre águas subterrâneas, sendo possível distinguir 12 subgrupos para as mesmas no âmbito dessa bacia.

Palavras-chave: qualidade da água, água subterrânea, análise estatística, bacia do Urussanga.

\begin{abstract}
Aquifers are important strategic reservoirs that should have their use prescribed after studies. Located on southern Santa Catarina State, the Urussanga River Basin cover an area of $680 \mathrm{~km}^{2}$ in which several uses of water resources can be found. Aiming at analyzing the quality of ground waters in the basin, the geochemical analysis of the water, most notably, and the spatial location of wells were made. Twelve variables of 30 groundwater collection sites were analyzed regarding: calcium, potassium, sodium, chlorides, sulfates, magnesium, manganese, iron, aluminium, $\mathrm{pH}$, conductivity and total alkalinity. The water was sampled from tubular wells, excavated wells, sources, representing different aquifer intervals. Using software of statistic processing, charts were prepared for the assessment of the primary components (Principal Compenents Analysis - PCA) and dendrograms. The crossing of the different analyses concluded that the deep aquifer waters are still with no interface with surface waters, which are already polluted. The synthesis of the statistical results allowed the construction of a panorama of groundwater, with 12 distinguishable subgroups for the groundwater within this basin.
\end{abstract}

Keywords: water quality, groundwater, statistical analysis, Urussanga basin. 


\section{INTRODUÇÃO}

Na Bacia do Rio Urussanga, SC, a água é uma importante fonte de vida, pois, além de ser utilizada para uso industrial e agropastoril, serve também para o abastecimento humano. Entretanto, o que se observa é que justamente o mau uso desse recurso vem trazendo inúmeros problemas para sua qualidade.

Esse estudo compreende uma análise estatística multivariada de dados hidrológicos da Bacia do Rio Urussanga (BRU). Tal iniciativa denota certa originalidade, pois oferece uma oportunidade para se averiguar o quanto alguns sais e metais estão concentrados em alguns pontos de coleta dentro da Bacia. A riqueza de componentes químicos dá-se pela diversidade geológica, como a Bacia Carbonífera Catarinense, que compõe parte dos terrenos rochosos da área.

$\mathrm{Na}$ tentativa de dar continuidade a levantamentos pioneiros realizados pela CPRM (Serviço Geológico do Brasil) e SIECESC (Sindicato das Indústrias de Extração do Carvão do Estado de Santa Catarina), foram selecionados, inicialmente, trinta pontos de coleta de água e doze variáveis químicas, que mesmo sendo de água subterrânea, são de quatro tipologias distintas: poços tubulares, ponteiras, poços escavados e fontes ou nascentes.

Os poços tubulares apresentam resultados de águas confinadas a mais de oitenta metros de profundidade em rocha sedimentar da Era Paleozoica. As ponteiras não ultrapassam quinze metros e captam água do lençol freático na planície costeira. Os poços escavados, diferentemente, apresentam uma espacialidade mais ampla na bacia. E, por fim, as fontes, localizadas nos limites da bacia ou em terrenos mais elevados, são locais de explotação de água de aquífero fraturado.

Para verificar as semelhanças de alguns casos e as variáveis mais influentes sobre os mesmos, optou-se pelas técnicas de análise de agrupamento (Cluster Analysis) e Análise de Componentes Principais (ACP). Ambas apresentaram resultados similares e complementares, o que facilitou o entendimento da carga metálica ou salina que cada poço, ponteira ou fonte carrega.

\subsection{OBJETIVOS}

Diante da necessidade de se contemplar estudos estatísticos sobre as águas subterrâneas da BRU, este trabalho apresenta os seguintes objetivos:

- Analisar, por meio da técnica ACP, de estatística multivariada, a importância das variáveis químicas nas águas subterrâneas da Bacia do Rio Urussanga (BRU). 
- Verificar o agrupamento das águas de poços e nascentes de acordo com sua similaridade, e conforme a importância de cada variável geoquímica.

- Espacializar os diferentes grupos de coleta num mapa base, bem como os resultados de subgrupos obtidos a partir de Cluster Analysis.

\section{CARACTERIZAÇÃO DA ÁREA}

A região carbonífera sul catarinense caracteriza-se pela predominância de extensas e espessas sequências de rochas sedimentares que se dispõem sobre uma base de rochas cristalinas do Pré-Cambriano e diferentes Formações e Membros da conhecida Coluna White são identificados na área de estudo. Conforme Krebs (2004), sobre essas litologias sedimentares gonduânicas assenta-se a Bacia do Rio Urussanga, cuja rede de canais pertencem à vertente atlântica. Seus afluentes estão instalados em vales estreitos e profundos na alta bacia e vales em "v" abertos na planície quaternária.

De acordo com Sant Ana (2008) a BRU localiza-se no sul catarinense, e possui uma área aproximada de $680 \mathrm{~km}^{2}$ e drena, total ou parcialmente, os municípios de Urussanga, Cocal do Sul, Criciúma, Içara, Morro da Fumaça, Treze de Maio, Pedras Grandes, Sangão, Balneário Rincão e Jaguaruna (Figura 1).

Figura 1 - Localização e divisão político-municipal na área de estudo
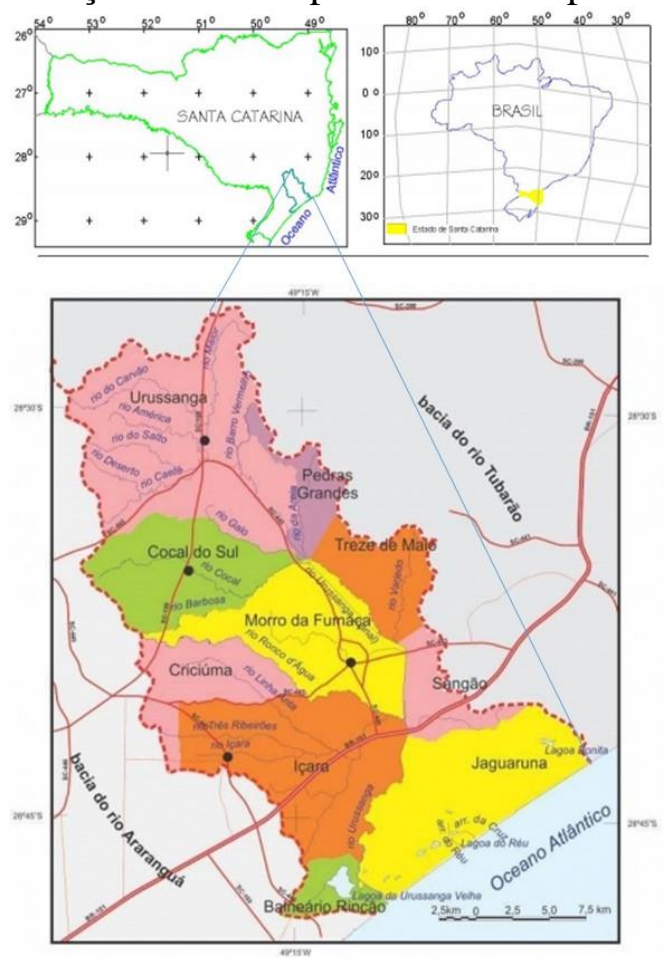

Fonte: Adaptado de Trein (2008) e do Comitê de Gerenciamento da Bacia Hidrográfica do Rio Urussanga (2016 
A Bacia do Rio Urussanga (BRU) recebe efluentes de variadas fontes, até a pouco tempo despejados, sem nenhum rigor, inclusive os industriais oriundos da mineração. O impacto ambiental incidente sobre os rios comprometem os aquíferos através de falhas geológicas, fraturas e demais zonas de recarga, onde as águas subterrâneas recebem contribuição das águas superficiais. Sabe-se que são os aquíferos que concentram a maioria das águas doces relativamente preservadas, representando assim, importantes reservas estratégicas. Desta forma, estudos hidroquímicos na área da BRU são importantes para o levantamento estatístico de dados hidrológicos.

Nas rochas sedimentares carbonosas em Santa Catarina, um importante mineral de ferro é a pirita. Águas subsuperficiais que apresentarem pH muito baixo, a exemplo das que estão em contato com a pirita, podem apresentar alto índice de ferro dissolvido. Indícios de baixo $\mathrm{pH}$ e da presença massiva de ferro, esse último observável através da coloração que a água adquire, foram diagnosticados nas águas superficiais da Bacia do Rio Urussanga. Veado (1989) e Espinosa (2001) mostraram que na BRU, os efeitos se faziam sentir praticamente ao longo de todos os quase $60 \mathrm{~km}$ de extensão do rio principal, apresentando teores de $\mathrm{pH}$ 3. É este grau de comprometimento dos recursos hídricos superficiais que pode comprometer as reservas estratégicas, que são as águas subterrâneas.

\section{MATERIAIS E MÉTODOS}

Os dados analisados neste estudo têm sua origem num levantamento hidroquímico realizado pela CPRM (Serviço Geológico do Brasil), da qual o autor principal fez parte, na ocasião em que os dados foram coletados e arquivados (entre 2005 e 2006), não tendo sido realizada análise exploratória de dados através de recursos estatísticos. Diante da não utilização desses dados por parte da instituição e por estar ciente que os mesmos possuem representatividade no conhecimento das características ambientais da referida bacia, estes autores preocuparam-se em tratar estatisticamente tais informações.

No procedimento de aquisição dos dados, optou-se pela estratégia amostral aleatória simples, levando-se em consideração os diferentes sistemas aquíferos e as variadas litologias presentes na BRU. Foi efetuada somente uma campanha de coleta durante o mês de dezembro de 2005, ocasião na qual foram coletadas oitenta e seis amostras de água. Destas, somente trinta foram aprovadas pelo LAQUA (Laboratório de Análises Químicas de Água) de Criciúma/SC. Foram escolhidas doze variáveis químicas, a saber: $\mathrm{pH}$, condutividade elétrica, alcalinidade total, cloreto, sulfatos, alumínio, cálcio, ferro, magnésio, manganês, potássio e sódio. 
Como pré-processamento das variáveis, conforme Landim (2011), elaborou-se histogramas no software Statistica ${ }^{\circledR}$, com o objetivo de verificar a normalidade da sequência. Através do resultado de "p" proposto por Shapiro-Wilk, constatou-se a possível normal. Como complemento, realizou-se o teste Chi quadrado $\left(X^{2}\right)$ para todas as doze variáveis, evitando-se a possibilidade de uma falsa normalidade. As variáveis foram transformadas em log-10, seno, arco-seno, raiz e, após essa etapa, padronizadas manualmente pelo software Excel $^{\circledR}$ ou pelo $M V S P^{\circledR}$. Nesta etapa, verificou-se que um ponto de coleta apresentava valores extrapolados em suas variáveis, o que denotava uma anomalia. Também uma das doze variáveis iniciais foi retirada da pesquisa porque não ocorreu índice significativo nos casos.

Uma das técnicas estatísticas adotada foi a de Ordenação ACP (Análise de Componentes Principais), que constitui-se numa simples estrutura de correlações sem hipótese priori a ser testada (LANDIM, 2011). Nela consegue-se obter importantes informações sem se postular causalidades, obtendo-se um conjunto de medidas correlacionadas linearmente. No software $M V S P^{\circledR}$ foi possível aplicar a técnica de ACP e verificou-se a qualidade de representação de uma variável através de gráficos bidimensionais euclidianos.

Outra técnica utilizada foi a Análise de Agrupamento (Cluster Analysis), que é utilizada para identificar similaridades entre casos e variáveis (MOITA NETO; MOITA, 1998). Ela reúne os dados em grupos discretos, relativamente homogêneos, com o intuito de diagnosticar descontinuidades com outros grupos. O resultado é expresso na forma de dendrograma. A estratégia de agrupamento usada foi a variância mínima (Ward), altamente eficiente na formação de grupos.

Inicialmente, partiu-se de uma tabela geral com trinta casos e doze variáveis mais as coordenadas UTM. A partir desta, separou-se poços tubulares dos escavados, ponteiras e fontes. Normalizou-se as doze variáveis seguindo o índice proposto por Shapiro-Wilk (p>0,05). Após esse passo, os dados foram transformados e padronizados, utilizando-se níveis de corte específicos para cada grupo de casos, pois cada um foi agrupado com as variáveis mais importantes determinadas a partir da sobreposição de vetores bidimensionais e matriz de similaridade obtida no $M V S P^{\circledR}$.

\section{RESULTADOS}

Os dados brutos de análise para os 30 pontos são apresentados na Tabela 1: 
Tabela 1: Tabela geral com os dados brutos das análises na BRU - Bacia Hidrográfica do Rio Urussanga

\begin{tabular}{|c|c|c|c|c|c|c|c|c|c|c|c|c|c|c|c|}
\hline \multicolumn{2}{|c|}{ ESTACAI GRUPO } & UTME & UTM N & $\mathrm{pH}$ & Cond. & Alc.Total & $\mathrm{Cl}$ & $\mathrm{SO} 4$ & $\mathrm{Al}$ & $\mathrm{Ca}$ & $\mathrm{Fe}$ & $\mathrm{Mg}$ & Mn & $\mathrm{K}$ & $\mathrm{Na}$ \\
\hline PT-01-PG-ur & PT & 671907 & 6837960 & 6.5 & 129 & \begin{tabular}{|l|}
28.2 \\
\end{tabular} & 8.8 & 12.2 & 1.36 & 1.63 & 0.26 & 2.1 & 0.000 & 1.96 & 15.67 \\
\hline PT-02-TM-ur & PT & 673591 & 6835855 & 6.9 & 83 & 14.8 & 6.6 & 12.3 & 0.78 & 0.23 & 0.00 & 0.34 & 0.140 & 1.14 & 13.33 \\
\hline PT-03-MF-ur & PT & 671856 & 6835308 & 6.8 & 223 & 66.8 & 9.6 & 13.6 & 1.15 & 3.12 & 0.71 & 4.38 & 0.000 & 2.70 & 18.68 \\
\hline PT-08-UR-ur & PT & 665178 & 6851012 & 6.8 & 248 & 73.3 & 10.1 & 25.5 & 1.64 & 6.38 & 0.15 & 5.47 & 0.000 & 1.43 & 15.8 \\
\hline PT-11-UR-ur & PT & 664000 & 6844306 & 5.9 & 137 & 37.6 & 8.5 & 14.3 & 1.62 & 0.83 & 0.04 & 2.96 & 0.000 & 4.41 & 7.44 \\
\hline PT-13-UR-ur & PT & 664672 & 6839115 & 5.5 & 91 & 7.9 & 9.7 & 11.9 & 0.44 & 0.25 & 0.00 & 2.01 & 0.000 & 4.69 & 6.91 \\
\hline PT-19-UR-ur & PT & 668158 & 6840082 & 7.4 & 419 & 117.8 & 9.6 & 31.6 & 1.17 & 19.27 & 0.48 & 6.96 & 0.000 & 1.63 & 42.53 \\
\hline PT-20-UR-ur & PT & 669035 & 6836215 & 7.3 & 354 & 107.4 & 17.6 & 14 & 1.31 & 20.5 & 0.53 & 4.78 & 0.000 & 1.92 & 31.28 \\
\hline PT-23-LS-ur & PT & 663615 & 6834689 & 7.6 & 425 & 110.4 & 29.1 & 22.8 & 2.1 & 11.19 & 0.05 & 3.29 & 0.000 & 2.30 & 58.9 \\
\hline PT-29-MF-un & PT & 674411 & 6829424 & 5.6 & 163 & 13.2 & 24.9 & 0 & 0.91 & 0.77 & 0.00 & 2.98 & 0.000 & 2.88 & 19.99 \\
\hline PT-30-MF-un & PT & 675810 & 6827614 & 7.7 & 1858 & 121.8 & 498.6 & 82.5 & 1.06 & 62.28 & 0.26 & 22.58 & 0.000 & 3.32 & 205.75 \\
\hline PT-38-IC -ur & PT & 664689 & 6831766 & 7.0 & 210 & 61.9 & 16.5 & 15.6 & 0.39 & 2.13 & 1.68 & 2.19 & 0.480 & 6.98 & 17.28 \\
\hline PT-64-IC-ur & PT & 666828 & 6824830 & 6.8 & 261 & 72.8 & 24.1 & 17.5 & 1.09 & 1.35 & 2.16 & 6.66 & 0.310 & 3.05 & 28.6 \\
\hline PO-04-JG-un & $\mathrm{PO}$ & 681180 & 6818440 & 5.6 & 187 & 4.7 & 14.8 & 13.3 & 0.37 & 5.82 & 0.05 & 4.01 & 0.000 & 7.88 & 10.09 \\
\hline PO-08-JG-un & $\mathrm{PO}$ & 686310 & 6820694 & 5.0 & 98 & 1.0 & 22 & 12 & 0.59 & 0.3 & 0.00 & 1.75 & 0.000 & 0.86 & 11.23 \\
\hline PO-19-JG-un & PO & 676488 & 6814268 & 5.8 & 137 & 3.3 & 19.6 & 0 & 0.19 & 1.52 & 0.26 & 2.92 & 0.510 & 0.38 & 13.89 \\
\hline PO-21-IC -ur & $\mathrm{PO}$ & 670959 & 6811283 & 6.7 & 82 & 8.9 & 11.6 & 12.1 & 0.84 & 3.15 & 0.00 & 1.15 & 0.000 & 1.16 & 5.47 \\
\hline PO-23-IC-ur & $\mathrm{PO}$ & 666991 & 6808405 & 4.9 & 54 & 0.0 & 8.2 & 0 & 0.09 & 0.37 & 0.00 & 1 & 0.000 & 0.79 & 4.89 \\
\hline PE-16-UR-un & $\mathrm{PE}$ & 660501 & 6848395 & 5.2 & 117 & 1.3 & 10.2 & 12.6 & 0.28 & 0.96 & 0.00 & 3.75 & 0.000 & 2.13 & 7.49 \\
\hline PE-21-UR-un & $\mathrm{PE}$ & 660449 & 6840518 & 4.7 & 92 & 0.0 & 6.9 & 21.6 & 3.5 & 0.56 & 0.46 & 1.92 & 0.000 & 5.78 & 2.95 \\
\hline PE-41-CR-un & $\mathrm{PE}$ & 666948 & 6828989 & 4.8 & 132 & 0.0 & 17.4 & 12.8 & 1.73 & 0.75 & 0.30 & 3.89 & 0.000 & 1.68 & 8.94 \\
\hline PE-66-IC-ur & $P E$ & 677224 & 6823720 & 4.9 & 103 & 0.0 & 14.6 & 12.6 & 2.07 & 0.59 & 0.07 & 1.64 & 0.370 & 1.82 & 8.87 \\
\hline PE-72-IC-ur & $\mathrm{PE}$ & 675010 & 6817028 & 5.4 & 165 & 4.6 & 20.1 & 11 & 1.62 & 3.34 & 0.18 & 2.55 & 0.130 & 2.87 & 13.34 \\
\hline FT-01-UR-ur & FT & 666311 & 6852782 & 5.2 & 37 & 0.7 & 5 & 0 & 2.38 & 0 & 0.57 & 0.98 & 0.000 & 1.02 & 2.79 \\
\hline FT-04-LS-ur & FT & 657505 & 6835810 & 6.3 & 93 & 26.7 & 6.1 & 13.6 & 2.41 & 0.33 & 0.34 & 3.07 & 0.000 & 0.82 & 6.11 \\
\hline FT-06-UR-ur & $\mathrm{FT}$ & 665452 & 6840990 & 6.3 & 52 & 5.0 & 7.6 & 14.8 & 0.24 & 0 & 0.41 & 0.92 & 0.000 & 3.51 & 5.72 \\
\hline FT-09-UR-ur & FT & 663327 & 6846426 & 5.6 & 73 & 7.6 & 6.4 & 0 & 1.91 & 0 & 0.06 & 1.85 & 0.000 & 1.44 & 6.41 \\
\hline FT-11-UR-ur & FT & 656510 & 6847020 & 6.7 & 72 & 15.8 & 4.2 & 19.8 & 2.14 & 0.32 & 0.19 & 2.26 & 0.000 & 1.16 & 4.32 \\
\hline FT-36-TM-ur & FT & 678170 & 6833223 & 6.6 & 68 & 7.9 & 8.7 & 13.5 & 1.1 & 0.57 & 0.56 & 1.33 & 0.000 & 1.60 & 7.09 \\
\hline FT-43-IC-ur & FT & 673664 & 6815631 & 6.3 & 105 & 3.3 & 15.2 & 13 & 0.35 & 0.68 & 0.22 & 3.83 & 0.000 & 0.45 & 11.96 \\
\hline
\end{tabular}

Legenda: $\mathrm{Pt}=$ poços tubulares, $\mathrm{Po}=$ ponteiras, $\mathrm{Pe}=$ poços escavados e $\mathrm{Ft}=$ fontes ou nascentes

Fonte: autores

Após a padronização e normalização, os dados foram importados para o software MVSP $^{\circledR}$. Neste programa efetuou-se uma Análise de Componentes Principais (ACP) resultando na matriz de similaridade, os eixos principais e a possibilidade de se averiguar os pesos das variáveis conforme distintos eixos (Tabela 2). Ressalta-se que estes dados foram inicialmente tratados, sob a técnica de ACP, com todas as variáveis e casos.

As matrizes obtidas por esta técnica não servem para elucidar importância ou redundância de variáveis se comparada aos gráficos euclidianos bidimensionais, obtidos como complemento de cada análise detalhada. A Figura 2 demonstra um gráfico bidimensional que cruza os eixos 1 e 2. Desta forma, as possíveis relações entre variáveis e casos puderam ser percebidas de início. 
Revista Tecnologia e Ambiente, v. 23, 2017, Criciúma, Santa Catarina/SC

ISSN Eletrônico 2358-9426 e ISSN Impresso 1413-8131

Tabela 2: Resultado do tratamento estatístico realizado pela técnica de ACP

\begin{tabular}{|c|c|c|c|c|c|c|c|c|c|c|c|c|c|}
\hline \multicolumn{14}{|c|}{ PCA todos os casos juntos } \\
\hline \multicolumn{2}{|c|}{ Similarity matrix } & \multirow{3}{*}{ Cond. } & \multirow{3}{*}{ Alc. Total } & \multirow[b]{2}{*}{ a } & \multirow[b]{2}{*}{ so4 } & \multirow[b]{2}{*}{ Al } & \multirow[b]{2}{*}{$\mathrm{Ca}$} & \multirow[b]{2}{*}{$\mathrm{Fe}$} & \multirow[b]{2}{*}{ Mg } & \multirow[b]{2}{*}{ Mn } & \multirow[b]{2}{*}{ k } & \multirow[b]{2}{*}{ Na } & \\
\hline & $\mathrm{pH}$ & & & & & & & & & & & & \\
\hline $\mathrm{pH}$ & 0.937 & & & & & & & & & & & & \\
\hline Cond. & 0.393 & 0.622 & & & & & & & & & & & \\
\hline $\begin{array}{l}\text { Alc, Total } \\
\text { a }\end{array}$ & $\begin{array}{l}0.839 \\
0.022\end{array}$ & $\begin{array}{l}0.534 \\
0.279\end{array}$ & $\begin{array}{r}0.956 \\
0.07\end{array}$ & 0.331 & & & & & & & & & \\
\hline 504 & $\begin{array}{l}0.022 \\
0.392\end{array}$ & $\begin{array}{r}0.279 \\
0.32\end{array}$ & 0.359 & 0.025 & 0.915 & & & & & & & & \\
\hline Al & -0.011 & 0.053 & 0.112 & .0 .146 & 0.182 & 1.036 & & & & & & & \\
\hline Ca & 0.454 & 0.563 & 0.503 & 0.201 & 0.309 & 0.043 & 0.698 & & & & & & \\
\hline $\mathrm{Fe}$ & 0.353 & 0.217 & 0.366 & 0.064 & 0.196 & 0.077 & 0.107 & 1.036 & & & & & \\
\hline Mg & 0.214 & 0.496 & 0.377 & 0.192 & 0.249 & 0.073 & 0.412 & 0.25 & 0.622 & & & & \\
\hline Mn & 0.04 & 0.13 & 0.012 & 0.213 & .0 .106 & -0.207 & .0 .026 & 0.453 & -0.004 & 1.028 & & & \\
\hline K & -0.038 & 0.224 & 0.169 & 0.075 & 0.319 & 0.015 & 0.132 & 0.266 & 0.115 & 0.055 & 1.017 & & \\
\hline \multirow[t]{2}{*}{$\mathrm{Na}$} & 0.473 & 0.565 & 0.545 & 0.307 & 0.209 & -0.071 & 0.493 & 0.2 & 0.379 & 0.173 & 0.053 & 0.639 & \\
\hline & $\mathrm{pH}$ & Cond. & Alc. Total & a & 504 & Al & $\mathrm{Ca}$ & $\mathrm{Fe}$ & $\mathrm{Mg}$ & Mn & K & $\mathrm{Na}$ & \\
\hline \multicolumn{2}{|c|}{ Eigenvalues } & & & & & & & & & & & & \\
\hline \multicolumn{2}{|c|}{ Cingentives } & ANos 1 & Avos 2 & Aves 3 & $A \times 0 s 4$ & Axas 5 & Axis 6 & Axis 7 & Axis 8 & Axis 9 & Axos 10 & Axos 11 & Axis 12 \\
\hline \multirow{2}{*}{\multicolumn{2}{|c|}{$\begin{array}{l}\text { Eigenvalues } \\
\text { Percentage }\end{array}$}} & 3.741 & 1.523 & 1.256 & $\quad 1.04$ & 0.836 & 0.524 & 0.459 & 0.191 & 0.183 & 0.051 & 0.028 & 0.005 \\
\hline & & 38.033 & 15.48 & 12.768 & 10.572 & 8.496 & 5.326 & 4.662 & 1.938 & 1.864 & 0.523 & 0.284 & 0.055 \\
\hline \multicolumn{2}{|c|}{ Cum. Percentage } & 38.033 & 53.513 & 66.281 & 76.853 & 85.349 & 90.675 & 95.337 & 97.275 & 99.138 & 99.661 & 99.945 & 100 \\
\hline \multirow{2}{*}{\multicolumn{2}{|c|}{ PCA variable loadings }} & & & & & & & & & & & & \\
\hline & & Avois 1 & Avis 2 & Avis 3 & Axis 4 & Axás 5 & Axis 6 & Axis 7 & Axis 8 & Axis 9 & Axis 10 & Axis 11 & Axos 12 \\
\hline $\mathrm{pH}$ & & 0.392 & $=0.083$ & $=0.196$ & 0.371 & $=0.393$ & .0 .001 & 0.168 & -0.079 & -0.021 & -0.331 & 0.585 & -0.147 \\
\hline Cond. & & 0.369 & 0.003 & $=0.074$ & -0.215 & 0.247 & -0.002 & .0 .03 & 0.049 & -0.008 & 0.212 & -0.062 & -0.836 \\
\hline Alc. Total & & 0.443 & -0.115 & -0.088 & 0.22 & .0 .204 & 0.293 & 0.223 & 0.393 & 0.043 & $=0.04$ & -0.614 & 0.153 \\
\hline a & & 0.124 & 0.186 & -0.123 & -0.255 & 0.236 & 0.084 & -0.011 & -0.179 & 0.541 & -0.675 & -0.16 & 0.027 \\
\hline 504 & & 0.277 & $=0.253$ & 0.305 & -0.111 & -0.267 & 0.793 & 0.148 & 0.052 & 0.079 & 0.053 & -0.129 & 0.062 \\
\hline Al & & 0.042 & 0.44 & 0.437 & 0.389 & 0.596 & .0 .003 & 0.29 & -0.041 & 0.081 & $=0.072$ & 0.092 & 0.036 \\
\hline Ca & & 0.347 & -0.12 & -0.17 & -0.192 & 0.154 & -0.006 & -0.049 & -0.607 & -0.564 & -0.055 & -0.169 & 0.233 \\
\hline $\mathrm{Fe}$ & & 0.26 & 0.393 & 0.417 & 0.39 & -0.04 & $-0,193$ & 0.528 & -0.319 & 0.112 & 0.083 & -0.105 & -0.043 \\
\hline Mg & & 0.284 & -0.04 & -0.026 & -0.177 & 0.327 & -0.081 & 0.515 & 0.53 & -0.251 & -0.192 & 0.283 & 0.215 \\
\hline Mn & & 0.086 & 0.711 & 0.075 & 0.156 & 0.208 & 0.348 & .0 .408 & 0.204 & -0.278 & -0.017 & 0.02 & 0.078 \\
\hline K & & 0.151 & 0.075 & 0.616 & -0.532 & -0.245 & -0.337 & -0.301 & 0.017 & -0.01 & -0.042 & 0.196 & 0.065 \\
\hline $\mathrm{Na}$ & & 0.349 & 0.075 & 0.247 & $=0.1$ & 0.162 & -0.009 & -0.107 & -0.083 & 0.469 & 0.576 & 0.26 & 0.371 \\
\hline
\end{tabular}

Fonte: autores

Figura 2: Cruzamento dos eixos 1 e 2

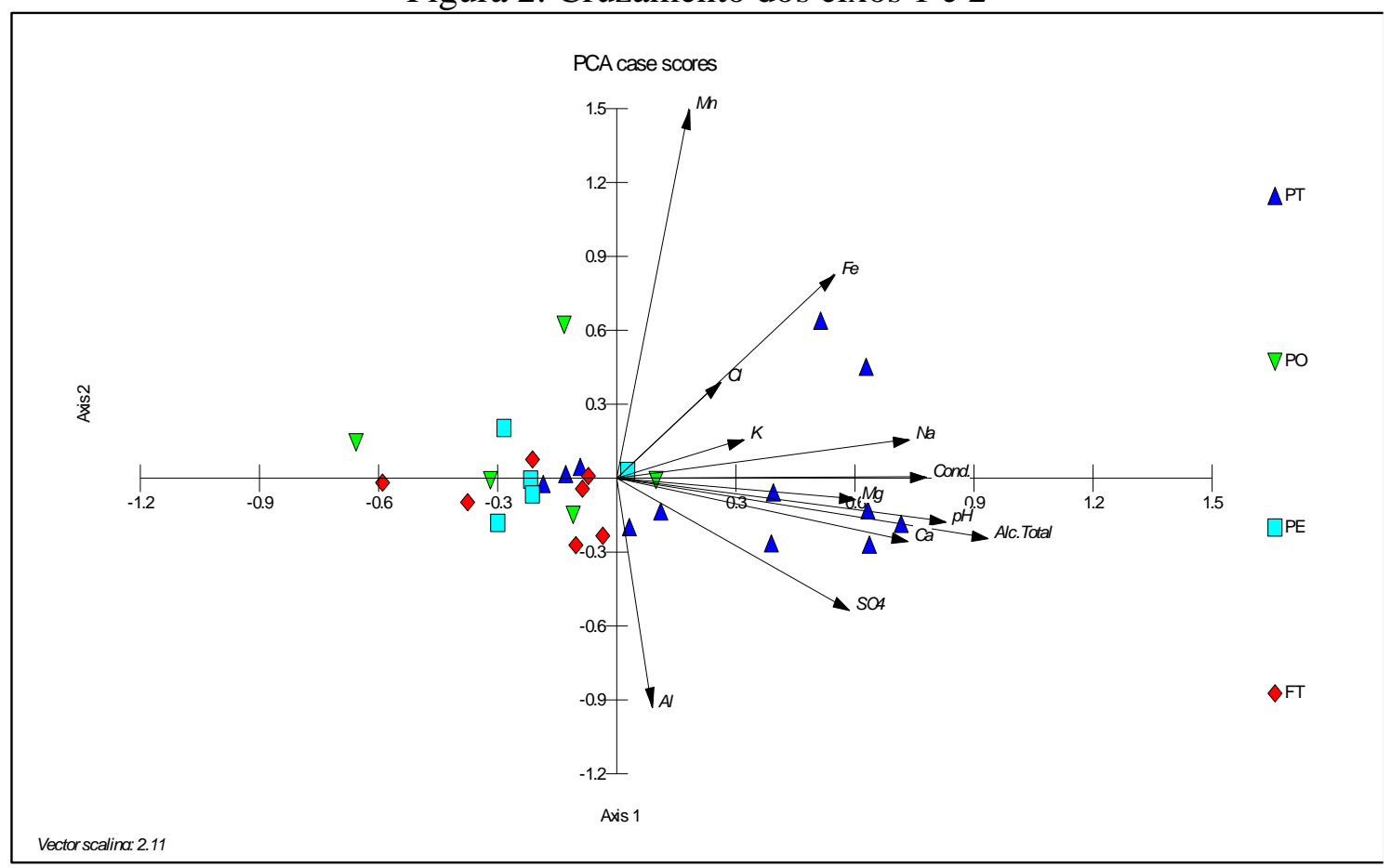

Legenda: $\mathrm{Pt}=$ poços tubulares, $\mathrm{Po}=$ ponteiras, $\mathrm{Pe}=$ poços escavados e $\mathrm{Ft}=$ fontes ou nascentes

Fonte: Do autor.

$\mathrm{Na}$ Figura 2 ficou evidente que as águas de poços tubulares apresentam maiores discrepâncias entre si, todavia, estão homogeneamente concentradas à direita do gráfico sob 
influência redundante de vários vetores de variáveis, das quais pode-se citar como as mais expressivas a alcalinidade total, os sulfatos e a condutividade.

As águas de poços escavados e fontes apresentaram maior proximidade no gráfico, já a representação das águas de ponteiras indicou que as mesmas possuem maiores diferenciações quanto aos constituintes geoquímicos. Outro aspecto denotado no gráfico relaciona-se ao fato de os poços tubulares apresentarem maior quantidade de sais e metais diluído em suas águas.

Todavia, para obter-se um resultado mais acurado, optou-se por tratar as quatro tipologias de águas subterrâneas da BRU de maneira particionada. Apresenta-se, na sequência, diagrama bidimensionais obtido na análise de principais componentes para poços tubulares e demais tipos de poços. Para efeito comparativo, realizou-se uma análise de agrupamento modo q (casos) para averiguar a similaridade dos pontos de coleta dentro da gama de casos.

\subsection{POÇOS TUBULARES}

Com base nas matrizes apresentadas na Tabela 2 e na redundância de vetores da Figura 2, determinou-se as variáveis mais influentes sob os poços tubulares (ferro total, potássio, magnésio, cálcio, condutividade e alumínio). A variável manganês, não foi normalizada e, consequentemente, foi retirada de todas as análises detalhadas de cluster e ACP. O poço PT-30 foi considerado um caso anômalo sendo retirado das análises.

No gráfico euclidiano bidimensional (Figura 3), exclusivo para poços tubulares, ficou evidente a separação de três grupos distintos de poços tubulares. O grupo 1: composto pelos pontos circulados em bege $(1,2,11,13$ e 29); o grupo 2: circulados em magenta $(3,8,19,20$ e 23) e o grupo 3 composto pelos pontos 38 e 64 . 
Figura 3: Gráfico exclusivo para poços tubulares

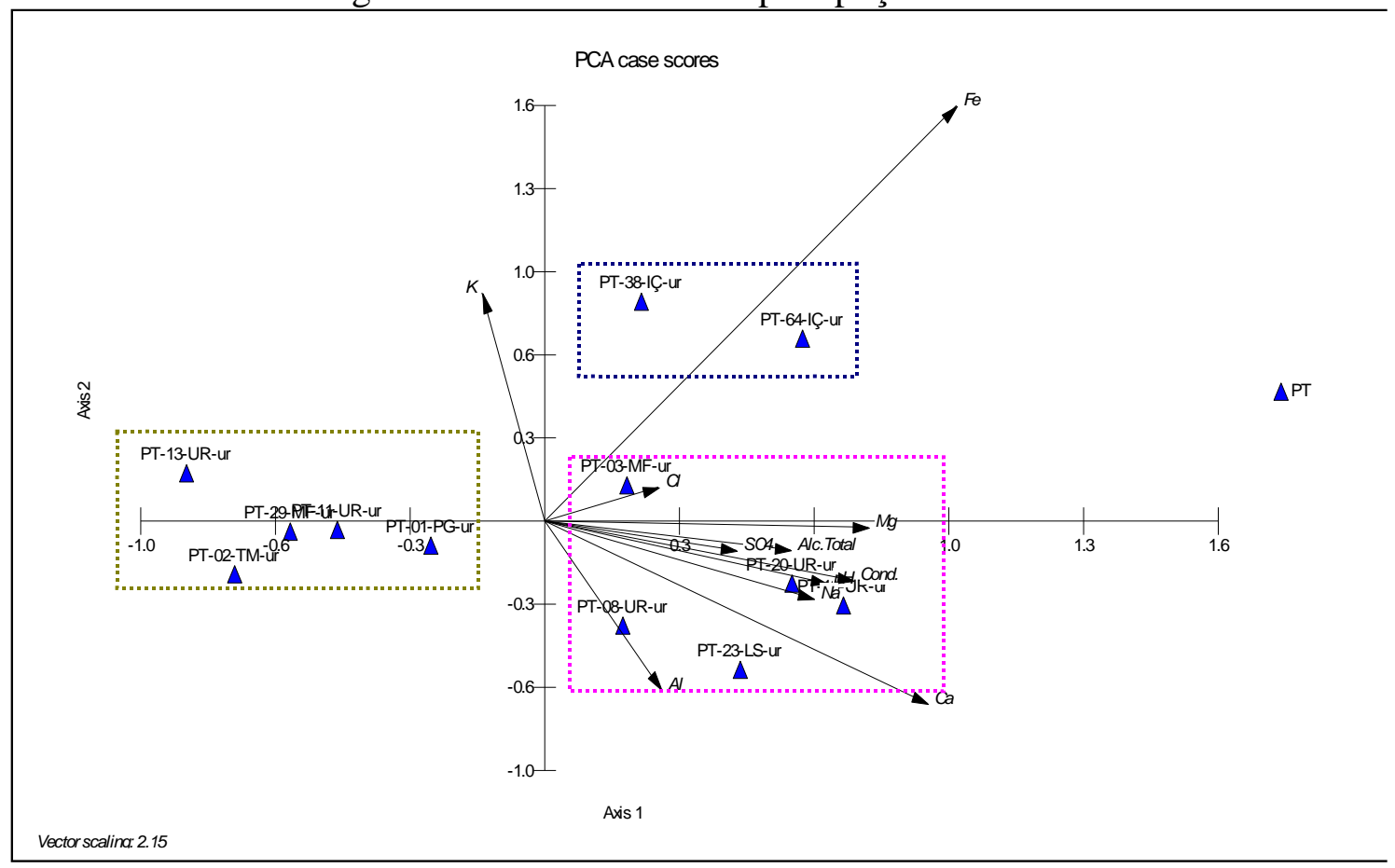

Fonte: autores

O grupo 1 é composto por poços tubulares que possuem pouco indício de sais e metais diluídos em suas águas. Ocupam posição à esquerda do gráfico bidimensional, justamente no oposto da direção dos vetores das variáveis. Possivelmente, são águas mais preservadas, com pouca fonte de contaminação superficial. Uma característica do grupo 1 é a natureza litológica granítica sobre as quais se encontra seus poços tubulares. Também ocupam porções com cotas altimétricas mais elevadas.

O grupo 2 congregou poços tubulares que possuem altas concentrações de cálcio, alumínio, sódio e magnésio. Obviamente, por possuir maiores taxas de miliequivalentes, a condutividade elétrica também demonstrou-se representativa. Os sulfatos são constituintes naturais das rochas da BRU, mas neste grupo aparece como uma variável secundária, assim como o cloreto.

As águas subterrâneas do grupo 2, possivelmente possuem interface com as águas superficiais da bacia, pois estas, há muito, estão fortemente impactadas por ferro, sulfatos e cloreto, fruto dos despejos industriais e da salinização. Coincidentemente, os poços componentes deste grupo assentam-se sobre litologias sedimentares semipermeáveis em áreas antigamente mineradas.

O grupo 3, em azul na Figura 3, apresenta dois pontos isolados, mas representativos no tocante à variável ferro. É explicável o forte condicionamento pelo vetor de ferro, pois os poços 
localizam-se nos limites dos municípios de Criciúma e Içara, local fortemente impactado ambientalmente e de acúmulo de material piritoso em depósitos de rejeito de minas antigas.

A Figura 4 demonstra dendrograma modo q (casos) com a similaridade dos poços tubulares. Esta análise foi complementar a ACP e nela averígua-se os mesmos grupos: em bege o grupo 1, em magenta o grupo 2 e em azul o grupo 3.

Figura 4: Dendrograma resultante da análise de agrupamento para poços tubulares.

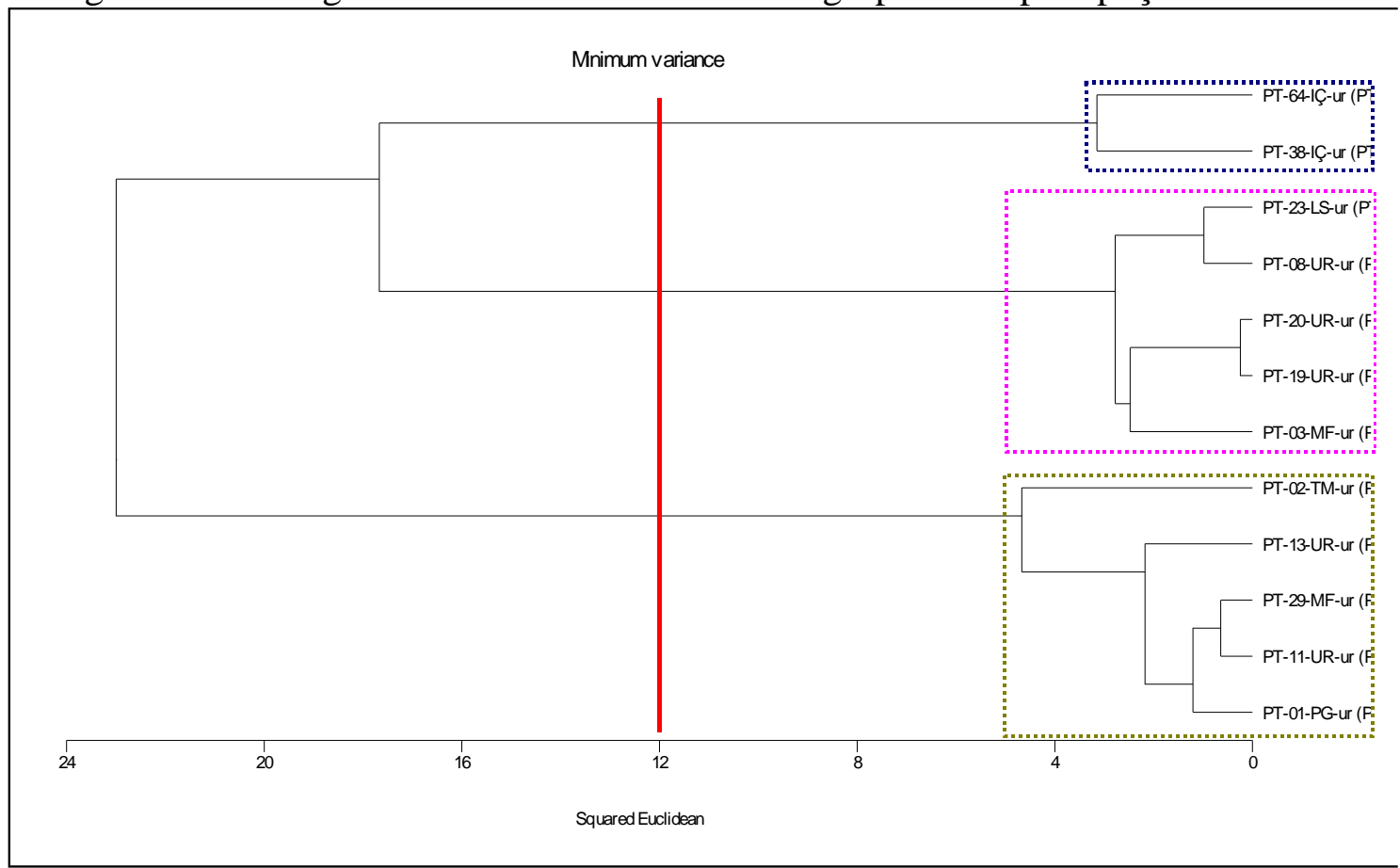

Fonte: autores

\subsection{PONTEIRAS}

As análises procedidas em ponteiras foram mais simples, pois tinha-se somente cinco casos. Para aplicação da ACP, cortou-se a variável anormal manganês e trabalhou-se com as demais resultando em três grupos distintos, Figura 5, como segue: em cinza o grupo 4 (ponto 4); em laranja o grupo 5 (pontos 8 e 21) e em azul o grupo 6 (pontos 19 e 23). 
Figura 5: Gráfico exclusivo para ponteiras

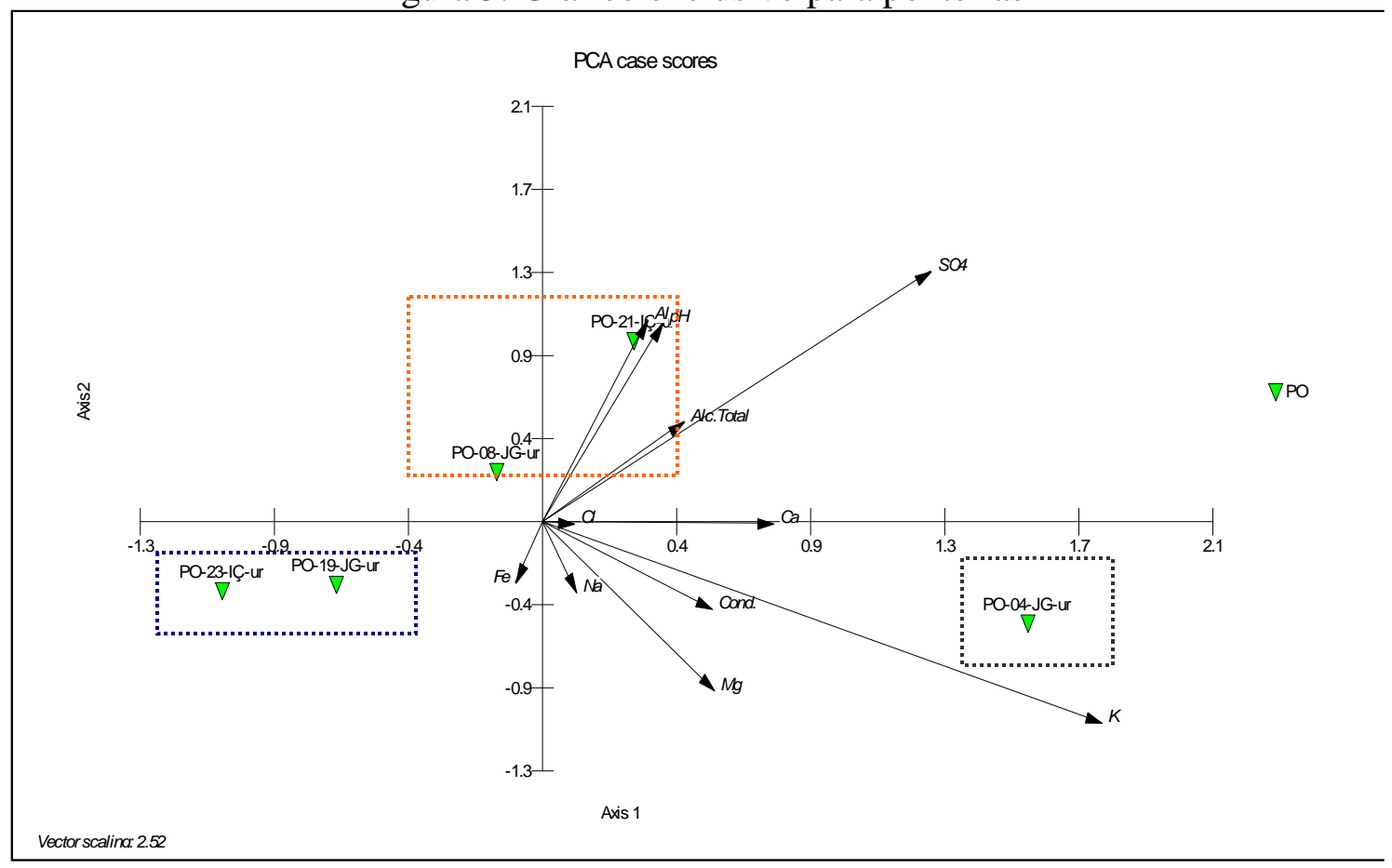

Fonte: autores

O grupo 4 apresenta caso fortemente influenciado pelo eixo 1 e pela variável potássio. Quanto ao grupo 5 é difícil chegar-se a uma conclusão, mas as variáveis sulfato, alumínio e pH determinam o ponto 21 , ao passo que o ponto 8 possui pouco magnésio e pouca condutividade (variáveis que nesta análise são diretamente proporcionais). O grupo 6 apresenta dois pontos com baixos índices de sais e metais.

De maneira complementar à ACP, na Figura 6, um dendrograma com a reunião dos mesmos grupos de similaridades identificados do gráfico bidimensional já apresentado. No dendrograma a linha vermelha representa o nível de corte e o grupo 4 está em cinza, o 5 em laranja e o 6 em azul.

As variáveis escolhidas para a análise de agrupamento dos pontos de coleta de água, correspondentes às ponteiras, foram as seguintes: ferro, cálcio, sulfato, potássio, magnésio e $\mathrm{pH}$. As ponteiras desta análise estão situadas na planície costeira, nos sedimentos quaternários de origem marinha. Com isso, esperava-se encontrar um peso maior das variáveis cloreto e sódio, denotando a contribuição marinha nas águas destes pontos de coleta, fato que não aconteceu. Esta constatação reforça a ideia de as ponteiras estarem explotando água do freático, sem captar a cunha salina do Oceano Atlântico. 
Figura 6: Dendrograma resultante da análise de agrupamento para ponteiras.

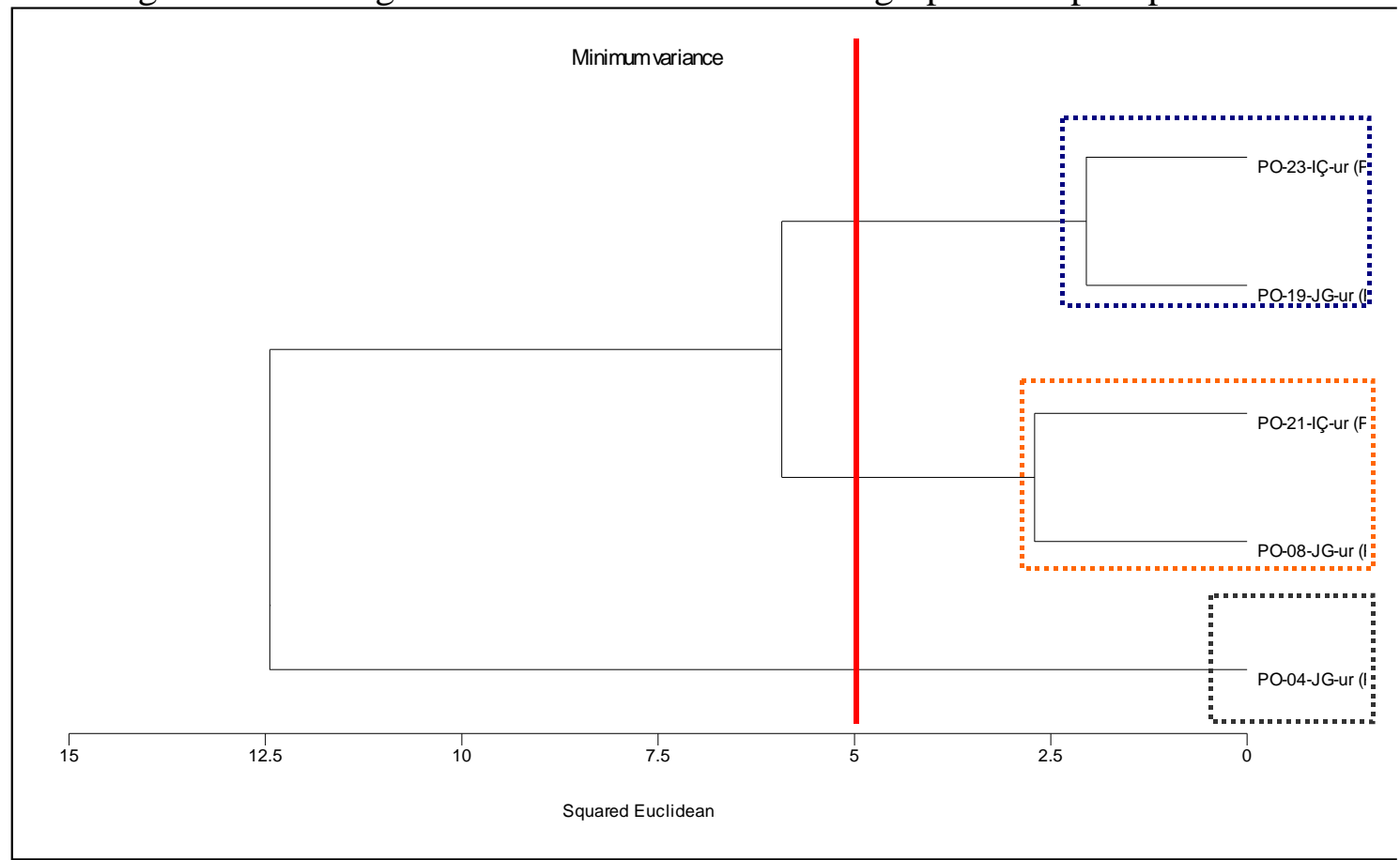

Fonte: autores

\subsection{POÇOS ESCAVADOS}

Os poços escavados foram cadastrados em toda a BRU sobre solos residuais de variadas litologias, desde a planície costeira até rochas ígneas e sedimentares. Na Figura 7, da ACP, identificaram-se três grupos espacialmente distintos: o grupo 7 em violeta (ponto 16), o grupo 8 em verde (ponto 21) e o grupo 9 em vermelho (pontos 41, 66 e 72).

O grupo 7 possui um poço escavado localizado sobre solo residual de rocha granítica, nas cabeceiras do Rio Urussanga. O forte peso da variável magnésio distingue este poço, bem como os baixos índices de ferro e alumínio.

No tocante ao grupo 8, localizado sobre rochas sedimentares, as variáveis mais significativas estão relacionadas aos despejos industriais existentes na imediação da coleta da água amostral do poço 21. O sulfato e o ferro são explicados pelas águas superficiais contaminadas com rejeitos de mineração. 
Figura 7: Gráfico exclusivo para poços escavados.

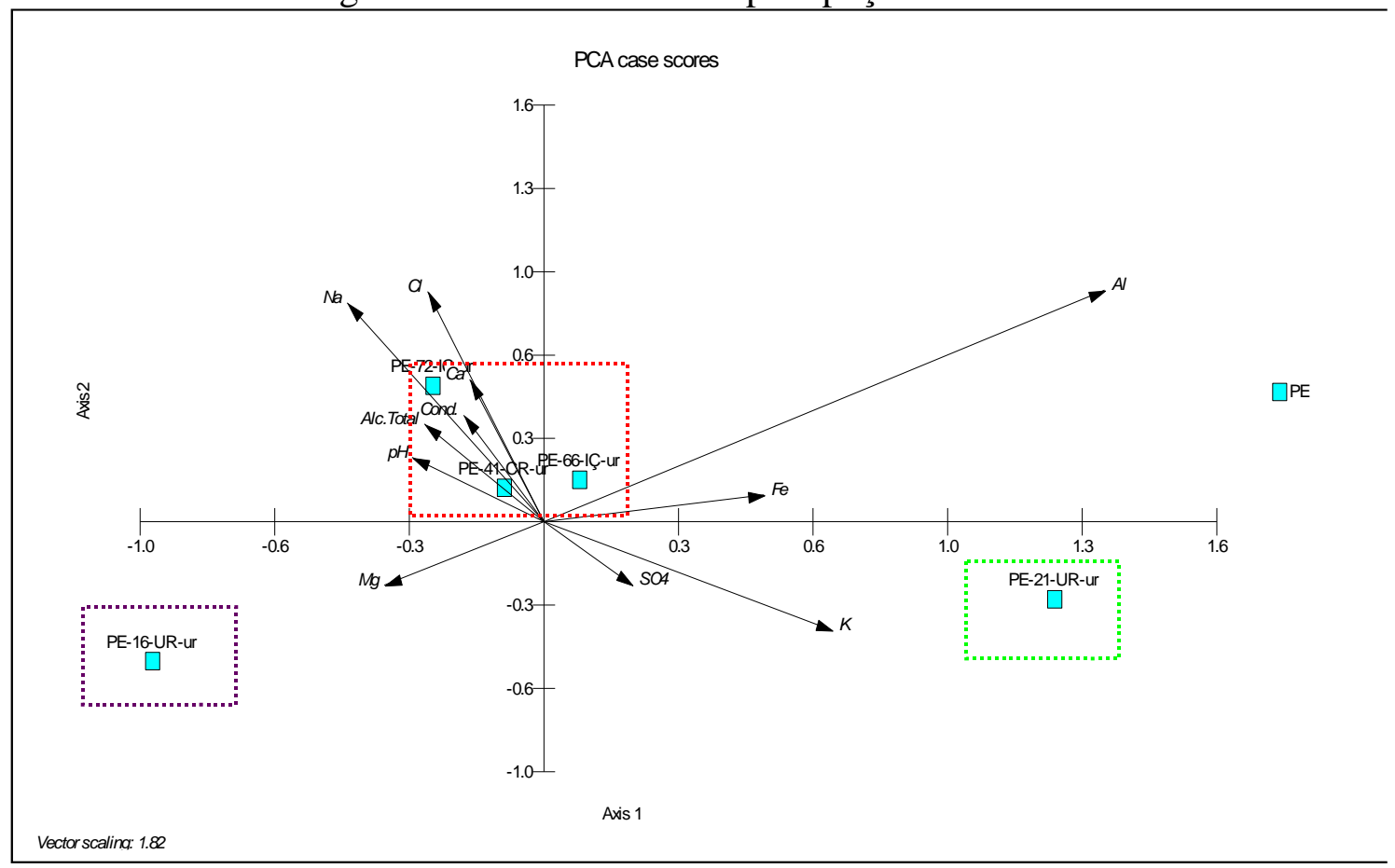

Fonte: autores

O grupo 9 apresenta as águas, possivelmente, mais preservadas quanto à proporção e significância das variáveis. Interessante perceber que a água do poço escavado 72 é levemente salobra, devido à presença de sódio e cloreto. Vale complementar que este poço se localiza próximo ao mar.

Para a análise de agrupamento modo $\mathrm{r}$ (variáveis) nos poços escavados foram escolhidas as variáveis mais significantes: potássio, sódio, cloreto, alumínio, magnésio e ferro. Representou-se o dendrograma do modo q (casos - Figura 8) e este serve para ratificar os dados propostos no gráfico da ACP. 
Figura 8: Dendrograma resultante da análise de agrupamento para poços escavados

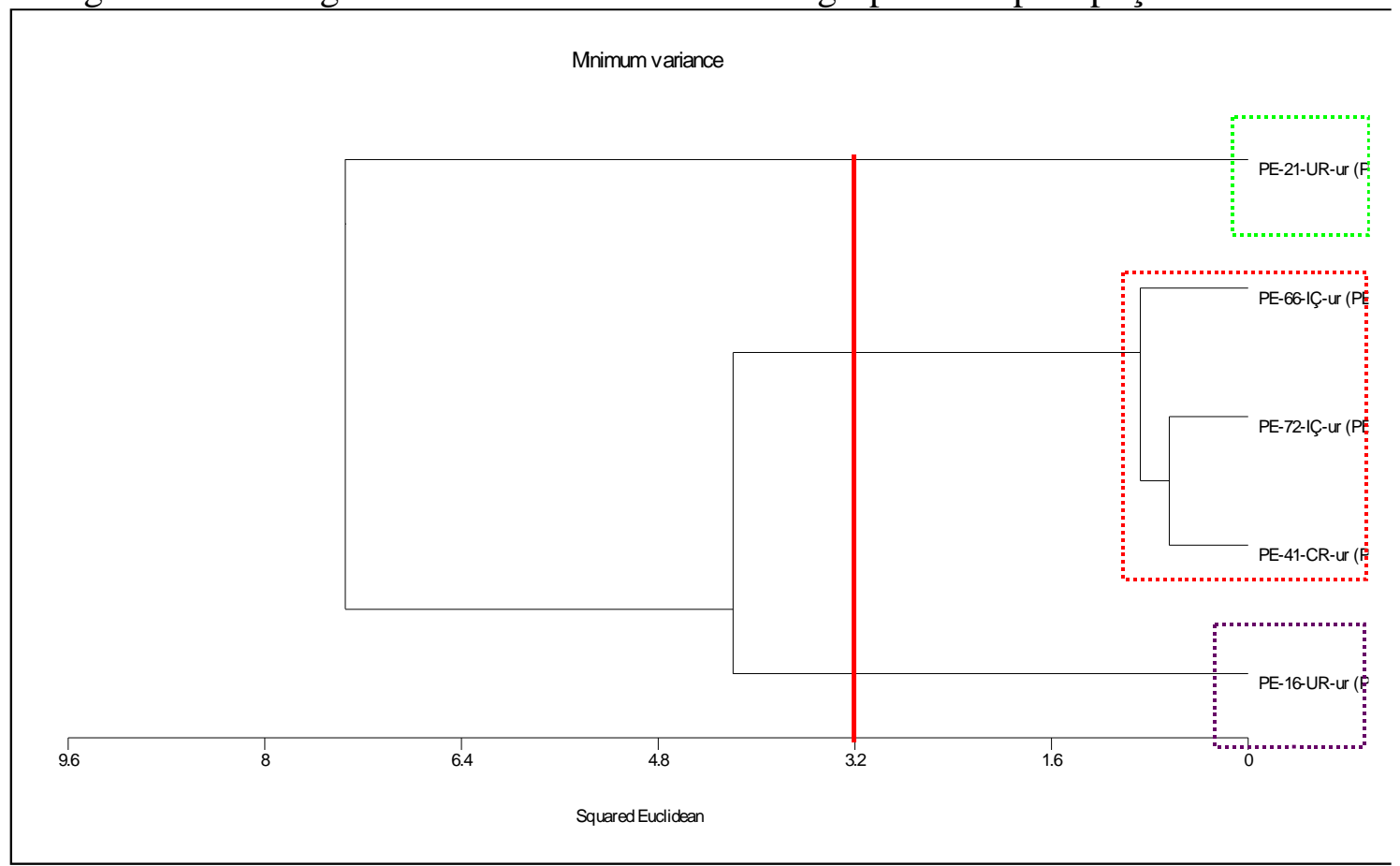

Fonte: autores

\subsection{FONTES}

As análises nas fontes ou nascentes de água também foram organizadas em três grupos (Figura 9). A cor rosa representa o grupo 10 (pontos 1 e 9), a cor azul representa o grupo 11 (pontos 4 e 11) e a cor laranja o grupo 12 (pontos 6, 36 e 46). As fontes localizam-se nas porções elevadas do terreno dentro da BRU, ou seja, nos extremos da bacia e em alguns morros testemunhos.

Os pontos de coleta do grupo 10 estão localizados na área de características ambientais preservadas da BRU. Como se pode ver através do gráfico, os dois pontos possuem pouca interferência hidroquímica na maioria das variáveis, como sulfato, $\mathrm{pH}$, magnésio. As fontes deste grupo são fortemente condicionadas pelo eixo 1 .

O grupo 11, em azul também congrega duas fontes. O substrato rochoso das fontes é de natureza sedimentar e o local de coleta é relativamente preservado. Como pode ser acompanhado na Figura 9, a variável magnésio e a alcalinidade total determinam, preferencialmente, a natureza destas águas. 
Figura 9: Gráfico exclusivo para fontes

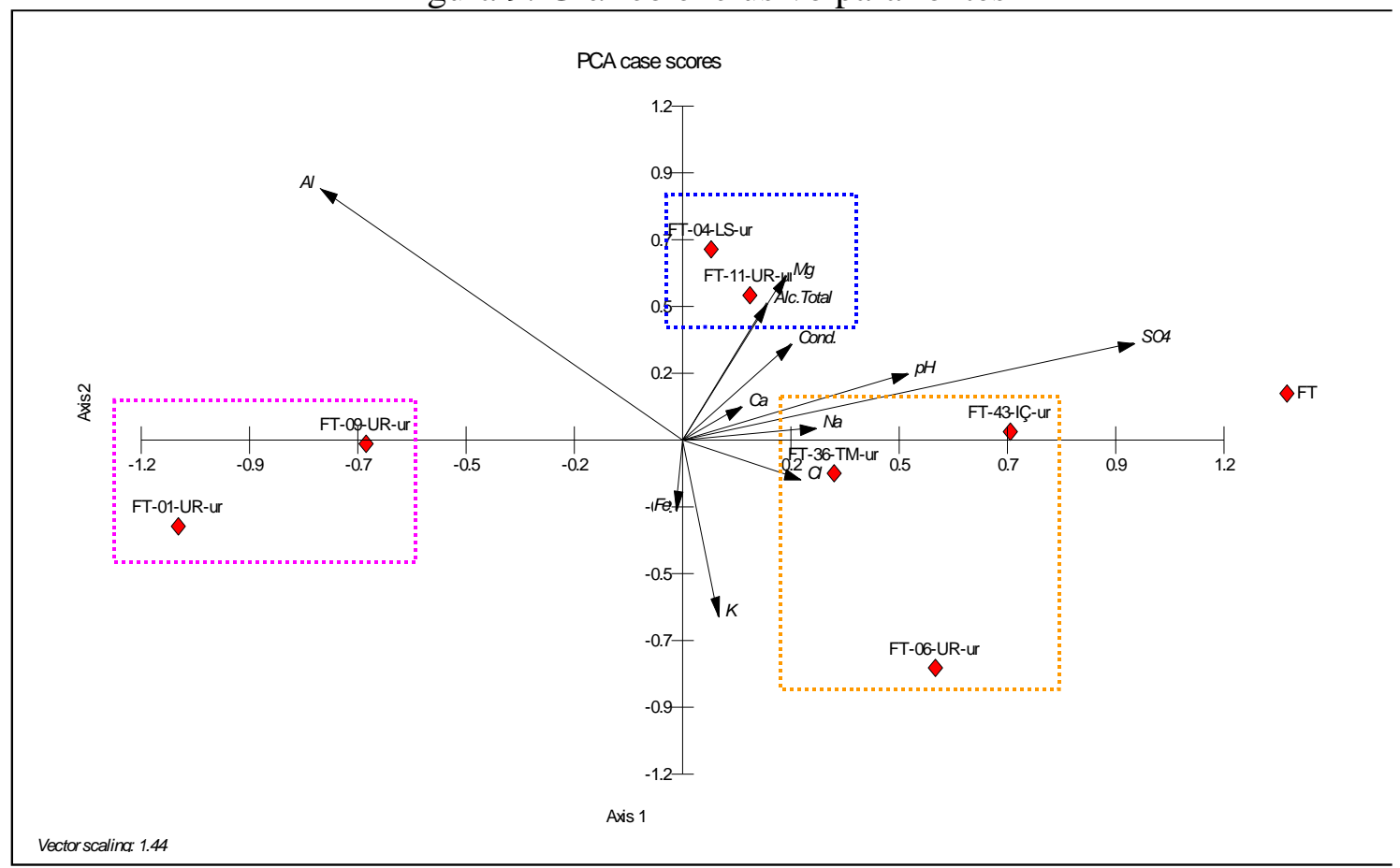

Fonte: autores

Existem três fontes alocadas dentro do grupo 12, em laranja, influenciadas mutuamente pela variável sódio, cloreto e potássio. No entanto, a fonte de número 6 , por estar localizada próxima ao litoral, apresentou água com elevada quantidade de cloreto e potássio. Esta referida fonte situa-se sobre planície costeira quaternária.

Fez-se um dendrograma modo $\mathrm{r}$ para as fontes utilizando-se das variáveis: potássio, sulfato, cloreto, magnésio, alumínio e ferro. Para efeito de comparação com a estratégia de $\mathrm{ACP}$, e procurando melhor explicá-la segue abaixo um dendrograma que compara à similaridade dos casos. É importante ressaltar, que os mesmos subgrupos formados na análise de agrupamento (ACP) reaparecem visualmente representados na Figura 10. 
Figura 10: Dendrograma resultante da análise de agrupamento para fontes

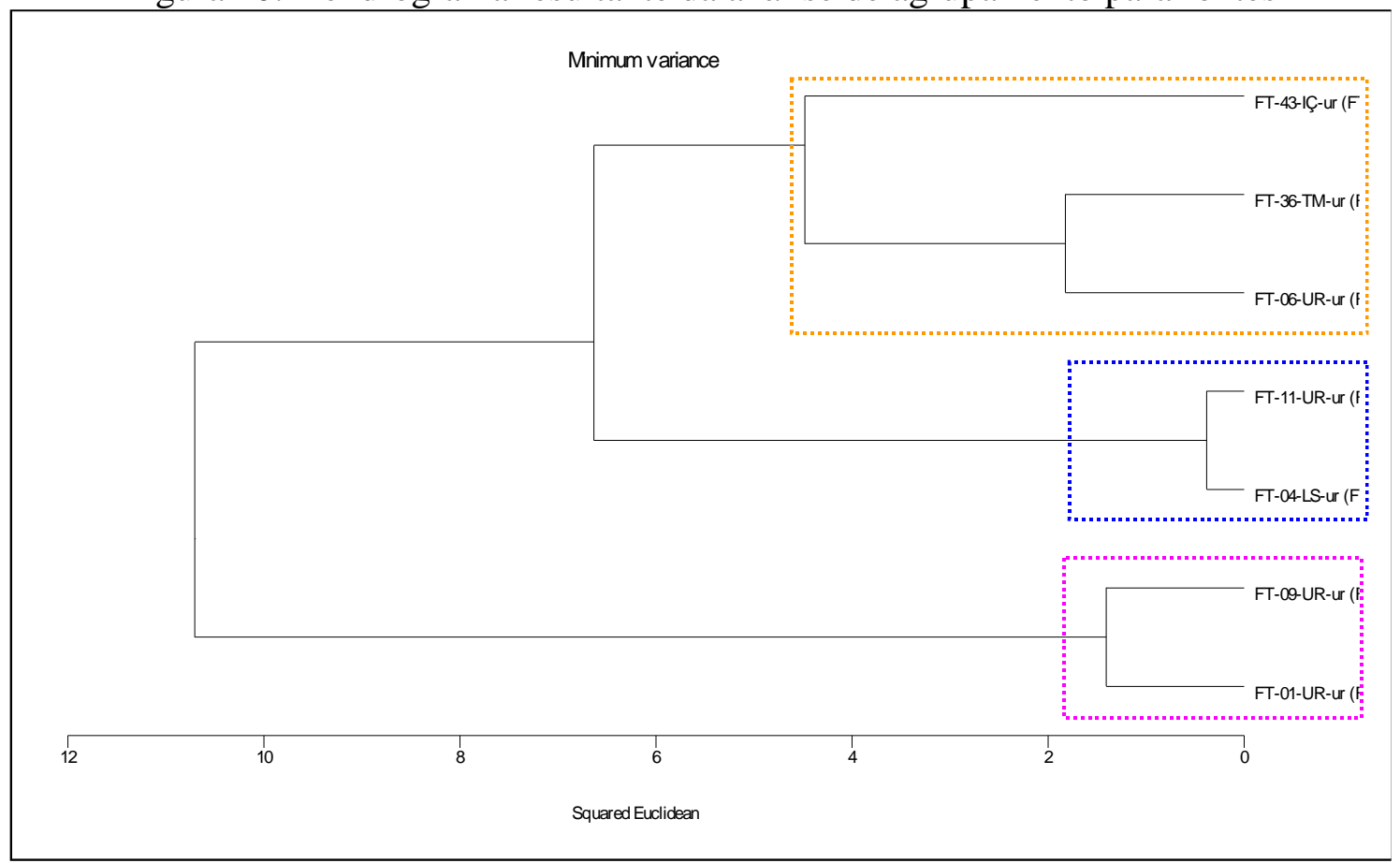

Fonte: autores

\section{CONCLUSÕES}

Os resultados obtidos através da análise de principais componentes (ACP) e agrupamento (cluster) foram esclarecedores para interpretação do comportamento geral das águas subterrâneas na Bacia do Rio Urussanga (BRU). Estas técnicas demonstraram ser complementares e a aplicação de uma deve preceder da outra quando se busca obter respostas elucidativas.

Outro aspecto identificado foi que as interpretações em ACP e cluster resultaram em subgrupos de casos, das quais muitos compostos por pontos isolados. Estes poços tubulares, ponteiras, fontes e poços escavados de onde foram coletadas as águas assentam-se sobre solos, ou mesmo rochas, de variadas constituições químicas.

Sabe-se que cada rocha possui um clarke diferenciado, principalmente àquelas formadas sob condições naturais específicas. Na BRU existem granitos paleozoicos, rochas sedimentares gonduânicas, basaltos e planície costeira quaternária. Cada rocha "libera" constituintes geoquímicos específicos em suas águas, por isso encontrou-se tamanha gama de variáveis representativas para as águas subterrâneas na referida Bacia.

Na Figura 11, observa-se a espacialidade dos pontos de coleta de água subterrânea dentro da BRU, na qual plotou-se os subgrupos reclassificados pela ACP e análise de cluster (agrupamento). Como se obteve três subgrupos para cada modalidade de coleta de água 
subterrânea (PT, PE, PO e FT), foram totalizados doze grupos apresentados nas análises específicas de agrupamento por similaridade e ACP. Estes subgrupos de 1 a 3 correspondem às águas de poços profundos, de 4 a 6 das ponteiras, de 7 a 9 dos poços escavados e de 10 a 12 das fontes, com diferentes simbologias, conforme suas características hidroquímicas definidoras da qualidade.

Figura 11: Mapa final com a plotagem dos subgrupos identificados por agrupamento de casos e análise de componentes principais.

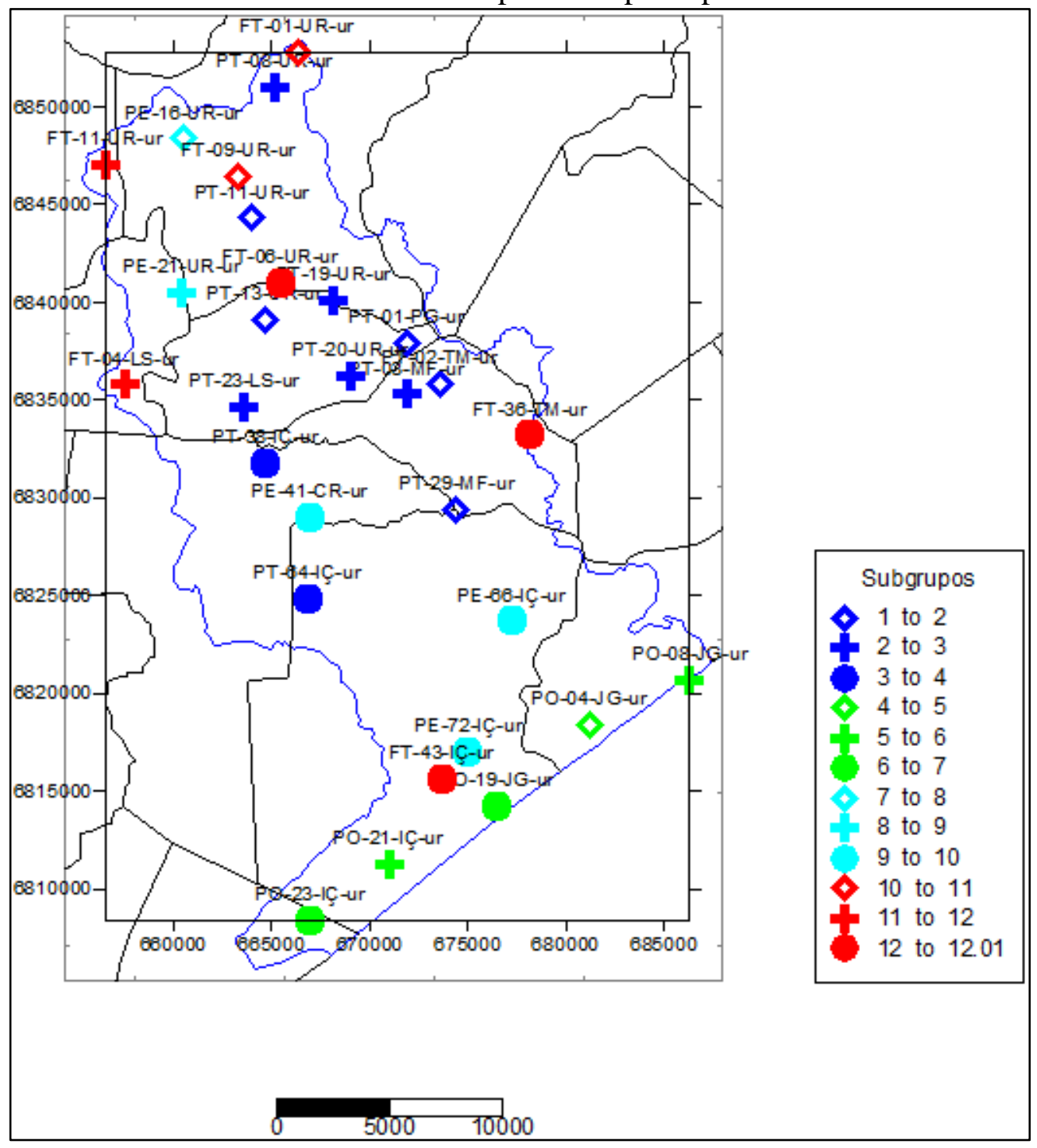

Fonte: autores

\section{REFERÊNCIAS}

COMITÊ DE GERENCIAMENTO BACIA HIDROGRÁFICA DO RIO URUSSANGA. Disponível em: http://www.aguas.sc.gov.br/a-bacia-rio-urussanga/bacia-hidrografica-riourussanga. Acesso 10 out. 2016.

ESPINOSA, H. R. M. Impactos e Conflitos na Gestão de Recursos Hídricos do Sul de Santa Catarina, Brasil. Tubarão: Grupo de Gestão e Pesquisa em Recursos Hídricos - GRUPERH, Universidade do Sul de Santa Catarina, 2001. 
KREBS, A. S. J. Contribuição ao Conhecimento dos Recursos Hídricos Subterrâneos da Bacia Hidrográfica do Rio Araranguá, SC. Tese de Doutorado, Programa de Pós-Graduação em Geografia, Florianópolis: UFSC, 2004.

LANDIM, P. M. B. Análise estatística de dados geológicos multivariados. São Paulo: Oficina de Textos, 2011.

MOITA NETO, J. M.; MOITA, G. C. Uma introdução à análise exploratória de dados multivariados. Teresina: Química Nova, v. 21, p. 467- 469, 1998.

SANT'ANA, W. de O. Qualidade dos Recursos hídricos Subterrâneos na Bacia do Rio Urussanga, SC. Dissertação (Mestrado) - Universidade Federal de Santa Catarina, Centro de Filosofia e Ciências Humanas. Programa de Pós-Graduação em Geografia. Florianópolis, 2008. $187 \mathrm{f}$.

SILVA, V. R. Caracterização Física e Uso do Solo na Microbacia do Rio Maior, Urussanga - SC. Dissertação de Mestrado, Programa de Pós-Graduação em Geografia, Florianópolis: UFSC, 1997.

TREIN, H. A. A implicação antrópica na qualidade dos Recursos hídricos subterrâneos da bacia hidrográfica do rio Urussanga - SC. Departamento de Geociências e Ciências Exatas. UNESP. Rio Claro, SP, 2008. 149p. (Tese de Doutorado).

VEADO, R. A. Análise Ambiental e a Qualidade das Águas na Bacia do Rio Urussanga. Dissertação de Mestrado, Programa de Pós-Graduação em Geografia, Florianópolis: UFSC, 1989. 